WellBeing International

WBI Studies Repository

$3-2000$

\title{
Bubble Ring Play of Bottlenose Dolphins (Tursiops truncatus): Implications for Cognition
}

\author{
Brenda McCowan \\ University of California - Davis \\ Lori Marino \\ Emory University \\ Erik Vance \\ Six Flags Marine World \\ Leah Walke \\ Six Flags Marine World \\ Diana Reiss \\ New York Aquarium
}

Follow this and additional works at: https://www.wellbeingintlstudiesrepository.org/acwp_asie

Part of the Animal Studies Commons, Behavior and Ethology Commons, and the Comparative Psychology Commons

\section{Recommended Citation}

McCowan, B., Marino, L., Vance, E., Walke, L., \& Reiss, D. (2000). Bubble ring play of bottlenose dolphins (Tursiops truncatus): implications for cognition. Journal of Comparative Psychology, 114(1), 98.

This material is brought to you for free and open access by WellBeing International. It has been accepted for inclusion by an authorized administrator of the WBI Studies Repository. For more information, please contact wbisr-info@wellbeingintl.org.

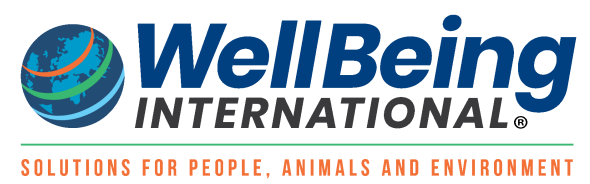




\title{
Bubble Ring Play of Bottlenose Dolphins (Tursiops truncatus): Implications for Cognition
}

\author{
Brenda McCowan ${ }^{1,3}$, Lori Marino², Erik Vance ${ }^{3}$, Leah Walke ${ }^{3}$, Diana Reiss ${ }^{4}$ \\ ${ }^{1}$ University of California, Davis \\ ${ }^{2}$ Emory University \\ ${ }^{3}$ Six Flags Marine World \\ ${ }^{4}$ New York Aquarium
}

\begin{abstract}
Research on the cognitive capacities of dolphins and other cetaceans (whales and porpoises) has importance for the study of comparative cognition, particularly with other large-brained social mammals, such as primates. One of the areas in which cetaceans can be compared with primates is that of object manipulation and physical causality, for which there is an abundant body of literature in primates. The authors supplemented qualitative observations with statistical methods to examine playful bouts of underwater bubble ring production and manipulation in 4 juvenile male captive bottlenose dolphins (Tursiops truncatus). The results are consistent with the hypothesis that dolphins monitor the quality of their bubble rings and anticipate their actions during bubble ring play.
\end{abstract}

Ongoing research into the cognitive capacities of dolphins and other cetaceans (e.g., whales and porpoises) has captured the interest and imagination of both the scientific community and the public (Herman, 1986; Reiss, McCowan, \& Marino, 1997). Bottlenose dolphins (Tursiops truncatus) are gregarious mammals that show a strong propensity for play behavior with physical objects and with conspecifics. There have been previous reports that both captive and wild dolphins produce their own objects of play, termed bubble rings (Marten, Shariff, Psarakos, \& White, 1996; Reiss, 1988, 1998; Tayler \& Saayman, 1973). During these events, dolphins expel air from their blowhole, and the expelled air rises to the surface in a torus or ringlike form. Marten et al. described the physics involved in the formation of the bubble ring as follows:

Any spherical bigger than about two centimeters in diameter will quickly become a ring because of the difference in water pressure above and below the bubble. Water pressure increases with depth, so the bottom of the bubble experiences a higher pressure than the top does. The pressure from below overcomes the surface tension of the sphere, punching a hole in the center to create a doughnut shape. As water rushes through the hole, a vortex forms around the bubble. Any vortex ring travels in the same direction as the flow through its center; in the case of these simple air rings, the vortex flow, in combination with the air's natural buoyancy, propels the bubbles toward the surface. (p. 84) 
Air-breathing dolphins always produce bubbles when they expel air underwater. Besides bubble rings, dolphins also produce a wide variety of other bubble types. They occasionally emit bubble streams concurrent with vocal activity. When surprised, curious, or excited, dolphins often emit a rapid exhalation termed a bubble burst. Breathing in dolphins, unlike in other mammals, is solely under voluntary control (Ridgway, 1972), a crucial feature in their adaptation to a fully aquatic existence. Whereas the physics of ring formation is straightforward (Lundgren \& Mansour, 1991), the actual production of stable rings may require some practice, expertise, and forethought by the dolphins.

Several researchers have examined object-related play (e.g., see Fagen, 1981; Hall, 1998, for reviews) and object manipulation in general (see Antinucci, 1989, 1990; Parker \& Gibson, 1979; Russon, Bard, \& Parker, 1996; Tomasello \& Call, 1997; Visalberghi \& Tomasello, 1998, for empirical and theoretical reviews of this issue) to gain insight into nonhuman levels of physical causal understanding (Kummer, 1995; Visalberghi \& Tomasello, 1998). We examined bouts of underwater bubble ring production and manipulation in 4 juvenile male captive bottlenose dolphins (Tursiops truncatus) to determine what this behavior may tell us about the dolphins' level of understanding in terms of the causal relations between objects.

Dolphins in different oceanariums have been reported to produce bubble rings. For example, Reiss $(1988,1998)$ reported that the dolphins would swim to the bottom of the pool, stop, assume a horizontal position, and then with a sharp upward jerk of the head, expel a ring of air through their blowhole. Marten et al. (1996) described a more varied repertoire of bubble ring production, including the production of both vertical and horizontal trajectories of the rings. In all three reports, the dolphins were described as exhibiting characteristic postures in specific locations in the water column just prior to the production of bubble rings. Reiss (1998) suggested that although dolphins release air in many forms, dolphins appear to control both the form and the timing of the release of air during the production of bubble rings. He further suggested that the dolphins' characteristic spatial positioning prior to bubble ring production provides suggestive evidence of "anticipatory behavior, an awareness of the contingencies of their past actions, and an awareness of the contingencies of future acts" (Reiss, 1998, p. 557).

Dolphins frequently manipulate their bubble rings by generating vortices around the objects, which cause the bubble rings to turn vertically by $90^{\circ}$ or flip in orientation $180^{\circ}$ (Marten et al., 1996; B. McCowan, personal observation). Bubble ring play can result in a sequence of two bubble rings, such that the second bubble ring joins the first bubble ring to form a large bubble ring, which is often then further manipulated. Sometimes a third smaller bubble ring extrudes from the larger ring as a result of the force of impact between the first and second bubble rings (B. McCowan, personal observation). This third bubble ring is frequently manipulated by the dolphins in a similar manner as described above for single rings where the dolphins vertically turn the bubble ring or completely flip the ring. However, not all second bubble rings catch and join first bubble rings, nor do dolphins always produce second bubble rings. In addition, bubble rings of variable quality can emerge depending on the integrity of the ring structure.

The present study represents the first systematic analysis of dolphins' bubble play behavior that goes beyond the anecdotal nature of prior observational studies. We examined several aspects of dolphins' bubble ring production by supplementing qualitative observations with quantitative ones, which allowed us to quantify the covariate relationships among the physical components of bubble ring behavior. Therefore, in this study, we move beyond solely descriptive observations to include a quantitative framework for testing hypotheses about the cognitive basis of these behaviors.

We provide qualitative observational descriptions of double bubble ring play behavior in 4 juvenile captive bottlenose dolphins. Furthermore, we used systematic quantitative analyses to uncover patterns in the dolphins' bubble ring behavior that may shed light on the level of cognition involved in this behavior. First, 
to establish the plausibility of an incentive for the dolphins to monitor the quality of their bubbles, we determined whether the quality of the first bubble ring is related to whether the second bubble ring, when it is produced, catches and joins the first. Second, to determine whether the dolphins monitor the quality of their bubble rings, we examined the association between the quality of the first bubble ring and the probability of producing a second bubble ring. Third, to determine whether the dolphins showed evidence of anticipatory planning, evidenced by positioning their bodies at lower depths immediately prior to the act of bubble ring production, we examined the association between location in the water column and play bubble production.

\section{Method}

\section{Subjects and Housing}

The subjects were 4 captive-born juvenile male bottlenose dolphins (Tursiops truncatus), ranging from 3 to 8 years of age, from Six Hags Marine World in Vallejo, California. The subjects were housed in an oval pool (dimensions: $18.0 \mathrm{~m}$ long $\times 12.0 \mathrm{~m}$ wide $\times 4.5 \mathrm{~m}$ deep; volume: 795,109 L) with an underwater viewing window at which observers collected data on the subjects' bubble behavior. Observers neither fed nor interacted with the dolphins immediately prior to, during, or immediately after an observational session. Six Hags Marine World trainers fed the dolphins during training and feeding sessions three to four times per day.

\section{Data Collection}

Data on bubble production and play were systematically collected using a focal animal event sampling design (Altmann, 1974). Each juvenile was observed for fifteen 30-min sessions over a 6-month period. The juveniles were between 3 and 8 years old at the time of the study. The order for sampling the subjects was pseudorandomly selected, and a total of two or three sessions were conducted each week between the hours of 8 a.m. and 5 p.m. A total of 718 bubble behavior events were collected over the 6 month period from the 4 male juveniles. Of the 718 events, 181 events were bubble ring play behavior and consisted of single and double bubble ring play. Social bubble behaviors, which included bubble bursts, bubble streams, and bubble clouds, were defined as tiny spherical bubbles in varying amounts and temporal sequence produced by individually identified dolphins during social surprise, whistle production, and chases between socially interactive individuals. Solitary play bubble behaviors were defined as bubbles produced by individually identified dolphins in nonsocial contexts that were frequently manipulated with their bodies, mouths, and toy objects or were occasionally simply observed or infrequently ignored after their production. These solitary play bubble behaviors included structurally discrete categories of bubble production: single conical bubbles, conical bubbles in sequence trails, and both single and double large torus-shaped bubbles, known as bubble rings (Marten et al., 1996; Reiss, 1988, 1998; see Table 1). Single bubble ring play behavior was defined as the production of a single ring (see Figure 1A for an example of dolphins' single ring production). Double bubble ring play behavior was defined as a close sequence of two bubble rings such that the second bubble ring was produced within 5 $s$ of the first ring production (regardless of quality; see below). The 5-s interval allowed the second ring the opportunity to join any first bubble ring to form a larger third ring.

Several categories of behavior associated with bubble ring and other bubble play production were collected. Table 2 presents a descriptive list of these variable behaviors. The observer collected the event data by narrating events into an audiocassette recorder. The type of bubble play event, the quality of bubble ring production (see below), the location in the water column where the dolphins engaged in bubble play production (interobserver reliability scores were unnecessary for the location where the dolphins engaged in bubble play because structural features in the dolphins' pool were used as markers 
to indicate depth [surface, middle, bottom]), and the presence of dolphin-initiated behaviors toward bubbles, such as second bubble ring production and biting of bubbles, were noted.

Table 1. Descriptive List of Bubble Play and Nonplay Behaviors Produced by 4 Juvenile Dolphins

\begin{tabular}{|c|c|c|}
\hline Behavior & Type & Description \\
\hline Bubble stream & Social & Line of single small bubbles usually released during vocalization \\
\hline Bubble burst & Social & $\begin{array}{l}\text { Large number of small bubbles simultaneously released during contexts of } \\
\text { surprise or fright }\end{array}$ \\
\hline Bubble cloud & Social & $\begin{array}{l}\text { Large number of small bubbles released during aggressive interaction with } \\
\text { conspecifics, especially during chases }\end{array}$ \\
\hline Single bubble & Solitary play & Single large bubble released and either manipulated by rostrum or bitten \\
\hline Bubble trail & Solitary play & $\begin{array}{l}\text { Line of single large bubbles released approximately } 1 \mathrm{ft}(0.3048 \mathrm{~m}) \text { apart, } \\
\text { frequently each of which is bitten in turn }\end{array}$ \\
\hline Single bubble ring & Solitary play & $\begin{array}{l}\text { Air bubble with a ring formation that is frequently manipulated in many and } \\
\text { complex ways }\end{array}$ \\
\hline Double bubble ring & Solitary play & $\begin{array}{l}\text { Two rings emitted sequentially (second ring produced within } 5 \mathrm{~s} \text { of first ring) } \\
\text { that sometimes join to produce one large ring }\end{array}$ \\
\hline
\end{tabular}

Figure 1. A: Photograph of a juvenile male dolphin producing a single bubble ring. B: Drawing of the categories of bubble ring quality.

A

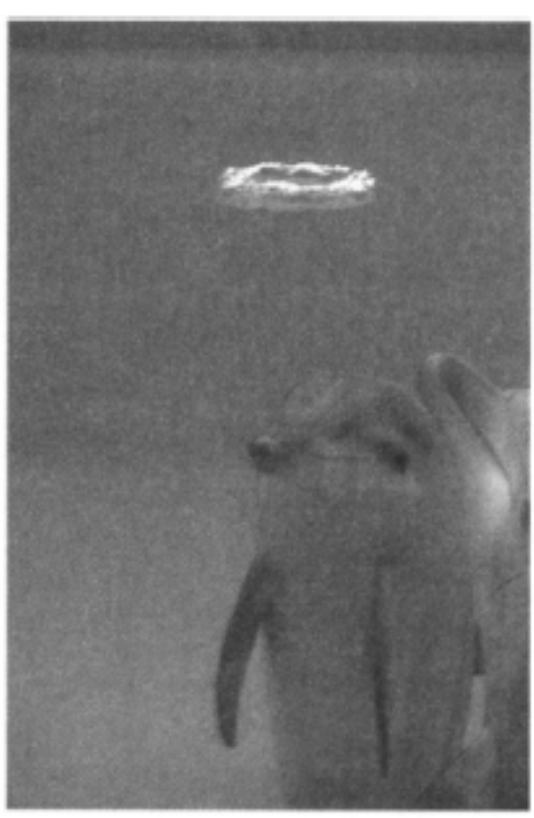

B

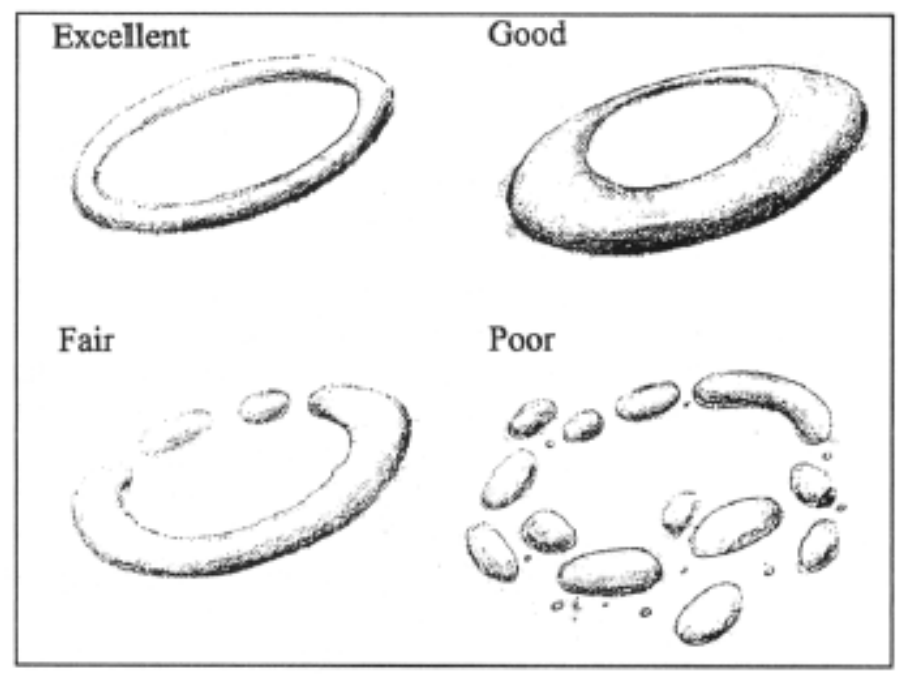

A 4-point scale was used to assess the quality of the first bubble ring production (Figure 1B) immediately after production, both prior to second bubble ring production when it occurred and when second ring production did not occur. Figure 1B shows representative examples of each category of bubble ring quality. The quality of a first bubble ring was assessed prior to the production of a second bubble ring by the subject to avoid any potential bias in bubble ring quality assessment. Although developing a quantitative test was an important objective for our study group and given the current limitations in 
quantitative video analysis, the quality of the bubble rings was determined by visual inspection of the bubble ring during each event. The quality of the bubble rings was determined by assessing the ring structure for both integrity (tightness) and completeness of the ring formation (see Figure 1B). Poor and fair rings exhibited partial and wide ring formations that differed in their degree of completeness. Good rings exhibited a complete but wide ring formation. Excellent rings exhibited both a complete and a very tight ring formation. One observer collected all of the event-based data and thus assessed the quality of each bubble ring event included in the data. However, to ensure that bubble ring quality was systematically analyzed, we conducted a post hoc interobserver reliability test between Brenda McCowan and the sole observer on the quality of the bubble rings by using videotapes collected during the study period on the bubble ring play of the subjects. Using 50 bubble ring events played back in real time on a VCR, we found that the interobserver reliability scores ranged from $90 \%$ to $97 \%$ by calculating a raw percentage of the correspondence between the two observers' ratings for each category of bubble ring quality.

\section{Data Analysis}

The data were entered into an Excel spreadsheet and coded for statistical analysis. First, we determined the relative amounts of bubble production for solitary play and social behaviors. Second, we assessed the relative amounts of different types of bubble play. Finally, we analyzed single and double bubble ring play with respect to a number of covariates, such as quality of bubble ring production, play behavior type, and the location where the dolphin was in the water column prior to the production of bubble rings versus other bubble play types. The variables tested were categorical in structure and included quality of bubble ring production (excellent vs. other) and location in water column (surface vs. middle vs. bottom). The outcomes, for example, catch and join (did vs. did not), production of second ring (yes vs. no), and bubble play event (ring vs. other), in each of the analyses were categorical and, more specifically, binary in structure. Thus, we used logistic regression as the statistical method (EGRET Reference Manual, 1997). Logistic regression is the statistical method of choice for binary data, because unlike other tests, such as chi-square, logistic regression indicates the significance as well as the magnitude of the association. Furthermore, logistic regression is free of a number of problematic distribution assumptions that affect other types of analyses.

Table 2. Descriptive List of Behaviors and Measures Collected on Bubble Play Events

\begin{tabular}{|c|c|}
\hline Behavior or measure & Description \\
\hline Quality of bubble ring & Excellent, good, fair, or poor (see Figure 1B and text) \\
\hline Location in water column & $\begin{array}{l}\text { The depth (in meters) in the water column at which production of each bubble play } \\
\text { event occurred }\end{array}$ \\
\hline Watch float & Dolphin explicitly observed bubble(s) float toward the surface \\
\hline Ignore & Dolphin departed from bubble(s) and engaged in another activity \\
\hline Bite & Dolphin bit bubble(s) \\
\hline Pectoral, rostral, or fluke swipe & Dolphin used pectoral fin, rostrum, or fluke to destroy bubble(s) \\
\hline Swim through & Dolphin swam through bubble(s) \\
\hline Rostral vertical turn play & $\begin{array}{l}\text { Dolphin manipulated without destroying single or double ring using the rostrum } \\
\text { and turned ring in a vertical fashion }\end{array}$ \\
\hline Catch and join & $\begin{array}{l}\text { A second ring in a double ring event caught and joined the first ring to form one } \\
\text { large double ring }\end{array}$ \\
\hline Ring extrusion & $\begin{array}{l}\text { A third smaller ring extruded from the impact of the second ring catching and } \\
\text { joining the first ring }\end{array}$ \\
\hline
\end{tabular}


Using mixed-effects logistic regression in EGRET statistical software for the PC (EGRET Reference Manual, 1997), we assessed the hypothesis that dolphins have an incentive to monitor the quality of their bubble rings during double ring events by analyzing the association between the quality of the first bubble ring and the probability that the two bubble rings in that event joined. We assessed the hypothesis that dolphins actually monitor the quality of their bubble rings by analyzing the relationship between the probability that subjects would blow a second bubble ring and the quality of their first bubble ring (excellent vs. other). Finally, we tested evidence for anticipatory planning of bubble ring production by the dolphins by analyzing the association between their location in the water column (as defined by pool depth: bottom vs. middle vs. surface) and the probability of their production of a bubble ring event versus other bubble play events. Because we studied 4 juvenile males by using a repeated measures design, we designated "individual" (the identity of each dolphin) as the random effect (or repeated measure) in each analysis (Searle, Casella, \& McCulloch 1992).

For all statistical tests, significance was evaluated at the .05 level. We conducted goodness-of-fit statistics for each model by using a likelihood-ratio chi-square statistic (Agresti, 1990). All models presented below exhibited appropriate goodness of fit.

\section{Results}

Types of Bubble Production and Bubble Play Events The dolphins produced six different categories of bubble events in solitary play and social contexts. The proportion of events for each category of bubble production is shown in Figure 2, which shows that bubble play events accounted for approximately $94 \%$ of all bubble events. When bubble play was considered alone, bubble ring play events accounted for approximately $25 \%$ of bubble play events that occurred. Bubble trails accounted for $40 \%$ of all bubble play behavior. Single bubbles accounted for $29 \%$ of total bubble play behavior. When bubble ring play was considered alone, single bubble rings ( $N=151)$ accounted for $83 \%$ and double bubble rings $(N=30)$ accounted for $17 \%$ of bubble ring events by the 4 subjects.

Figure 2. Proportion of events for bubble production types.

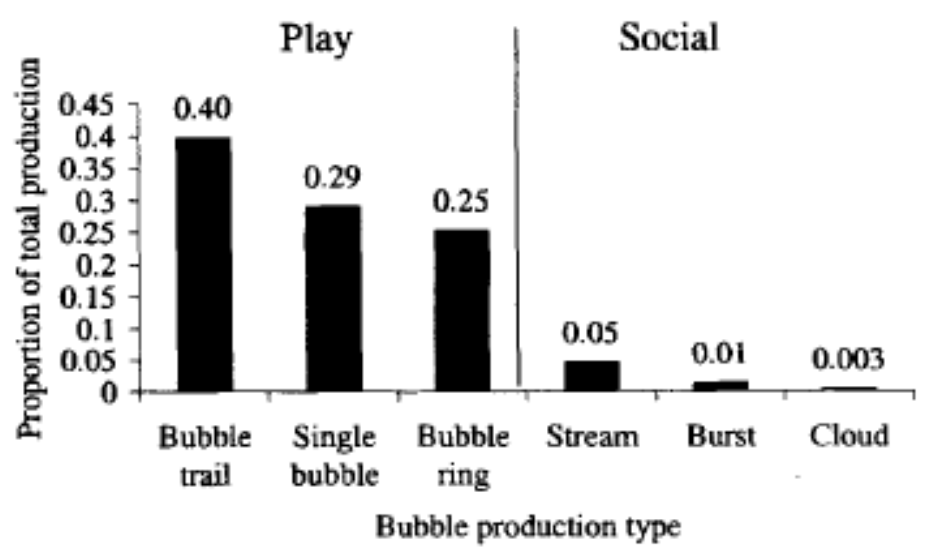


Table 3. Raw Data on Bubble Ring Play Behavior Events and Measures for Each Juvenile Subject

\begin{tabular}{|c|c|c|c|c|}
\hline \multirow{2}{*}{ Bubble ring production and outcome } & \multicolumn{4}{|c|}{ Subject } \\
\hline & Avalon & Brisbee & Liberty & Norman \\
\hline Single ring production & 88 & 13 & 20 & 30 \\
\hline Excellent quality & 28 & 4 & 7 & 2 \\
\hline Other quality & 58 & 9 & 12 & 23 \\
\hline Quality data missing $^{\mathbf{a}}$ & 2 & 0 & 1 & 5 \\
\hline Water column: Top & 1 & 0 & 0 & 2 \\
\hline Water column: Middle & 20 & 3 & 3 & 5 \\
\hline Water column: Bottom & 63 & 10 & 17 & 15 \\
\hline Water column: Data missing ${ }^{\mathbf{a}}$ & 4 & 2 & 0 & 8 \\
\hline Double ring production & 13 & 9 & 1 & 7 \\
\hline Excellent quality $^{\mathbf{b}}$ & 9 & 8 & 1 & 6 \\
\hline Other quality & 4 & 1 & 0 & 0 \\
\hline Quality data missing $^{\mathbf{a}}$ & 0 & 0 & 0 & 1 \\
\hline Water column: Top & 0 & 0 & 0 & 0 \\
\hline Water column: Middle & 1 & 0 & 0 & 1 \\
\hline Water column: Bottom & 12 & 9 & 1 & 5 \\
\hline Water column: Data missing ${ }^{\mathbf{a}}$ & 0 & 0 & 0 & 1 \\
\hline Catch and join & 5 & 4 & 0 & 3 \\
\hline Ring extrusion & 2 & 1 & 0 & 1 \\
\hline \multicolumn{5}{|l|}{ Response to or manipulation of bubble ring } \\
\hline Watch float $^{\mathbf{c}}$ & 22 & 0 & 0 & 0 \\
\hline Rostral vertical turn & 13 & 2 & 0 & 0 \\
\hline Swim through & 1 & 0 & 0 & 3 \\
\hline Rostral swipe & 1 & 2 & 0 & 0 \\
\hline Pectoral swipe & 1 & 0 & 0 & 0 \\
\hline Ignore & 10 & 2 & 0 & 4 \\
\hline Bite & 88 & 18 & 21 & 30 \\
\hline
\end{tabular}

a Observation of this measure was missing for the number of events indicated for each subject

b Represents the quality of the first ring in the double bubble ring event.

c This category represents explicit observation of bubble rings; all bubble rings had to be implicitly observed when subsequent manipulation occurred.

Table 3 presents the raw data on the types of bubble ring events, the quality and location of such events, and the postproduction observation and manipulation of bubble rings for each subject. As indicated in Table 3, bubble ring production and manipulation were variable both within and between the juvenile subjects. All of the dolphins must have implicitly observed their bubble rings visually or by echolocation prior to any postproduction manipulation of bubble ring events (note that the category ignore did not involve postproduction observation but consisted of only $11 \%-13 \%$ of the bubble ring events across subjects; $87 \%-89 \%$ of all bubble rings were manipulated by the subjects). However, explicit visual observation was identified when the dolphins faced and closely followed the trajectory of the bubble production, as observed for Avalon in Table 3. The most frequent final response for all subjects was to bite and thus destroy the bubble rings (Table 3). Other destructive behaviors included pectoral, fluke, and 
rostral swiping of the rings (Table 3). In addition, some manipulations were more complex than others. Two of the dolphins generated vortices around the bubble rings, thus causing the rings to turn vertically by $90^{\circ}$ or to completely flip in orientation by $180^{\circ}$. We termed this behavior rostral vertical turn (Table 3; Marten et al., 1996; B. McCowan, personal observation). Sometimes during double ring play, the second ring caught up and joined the first ring and generated a third smaller bubble ring resulting from the force of impact between the first and second bubble rings, which we termed ring extrusion (Table 3). This third bubble ring was sometimes manipulated by the dolphins in a similar manner as described above for single rings when the dolphins vertically turned the bubble ring or completely flipped the ring ( $B$. McCowan, personal observation). However, not all second bubble rings catch and join first bubble rings ( $50 \%$ of all double bubble ring events), nor do dolphins always produce second bubble rings ( $17 \%$ of all bubble ring events were double bubble ring events).

\section{Quality of First Bubble Ring and Probability of Second Bubble Ring Production}

To determine whether there would be any incentive by the dolphins to monitor the quality of first bubble ring production, we needed to establish that the quality of the first bubble ring was associated with whether a second bubble ring would successfully catch and join the first ring. Indeed, such an association was found (Figure $3 A ; \beta=3.1, p<.005$, odds ratio $[O R]=21.8, d f=169$ ). Second bubble rings produced after "excellent" first bubble rings showed an OR of approximately 22:1 in catching and joining first rings over second bubble rings produced after "other" first bubble rings. This extremely high OR indicates that excellent quality first rings are highly associated with the successful fusion of second and first rings.

As indicated above, bubble ring play behavior can be highly variable and thus may be useful in revealing what dolphins understand about physical causation. We tested whether the double bubble ring behavior of the subjects was consistent with the notion that dolphins make decisions about whether to produce a second bubble ring that are contingent on the probability of the second ring catching up and joining the first ring. Therefore, given that the quality of the first ring is related to whether a second ring will successfully catch and join it, we examined whether the dolphin's own behavior reflected this contingency by analyzing the association between the quality of the first bubble ring and the probability of production of a second bubble ring by the same dolphin. The association between quality of the first bubble ring and whether each dolphin produced a second bubble ring was highly significant (Figure 3B; $\beta=7.8, p<.002$, $\mathrm{OR}=8,1, d f=169)$. It is very important to note that this result was not a function of all rings being of excellent quality (single rings: $\mathrm{N}=151,27 \%$ excellent, $73 \%$ other; first ring of double rings: $\mathrm{N}=30,80 \%$ excellent, $20 \%$ other). The proportions of single bubble rings versus the first ring of double rings that were of excellent versus other quality also differed substantially for each of the subjects (Table 3). Therefore, these results established a plausible incentive for dolphins to monitor the quality of bubble rings because the quality of the first ring is strongly correlated with whether a second bubble ring will catch and join the first. In addition, these results provide evidence that dolphins actually do monitor the quality of their first bubble rings before deciding whether to produce a second bubble ring during this play behavior.

\section{Spatial Location of Bubble Ring Production}

We further tested whether the dolphins moved to a specific location in the water column to produce both single and double bubble rings versus other types of bubble play behavior. A significant outcome for this test would be consistent with the notion that dolphins show anticipatory planning if dolphins physically position themselves at a specified location in the water column before producing bubble tings but not other types of bubble play behaviors. As we predicted, the dolphins did produce bubble tings in a specified location in the water column, which was usually near the bottom of the pool (Figure 4; bottom:

$\beta=3.3, p<.001, \mathrm{OR}=37.5, d f=424$; middle: $\beta=2.2, p<.001, \mathrm{OR}=9.5, d f=424)$. Importantly, this result was independent of the quality of rings produced $(\beta=21.7, d f=159, p=1.0)$, indicating that all 
types of bubble rings, whether single or double or whether of low or high quality, were produced at a specific location by the dolphins (also see Table 3). Therefore, the location of the water column did not affect the quality of the ring produced by the dolphins, only whether the dolphins produced a bubble ring versus another type of bubble play event.

Figure 3. Logistic regression model for the association between the quality of the first ring and the joining of the second ring $(A)$ and the quality of the first ring and the production of a second ring by the dolphins (B).

A

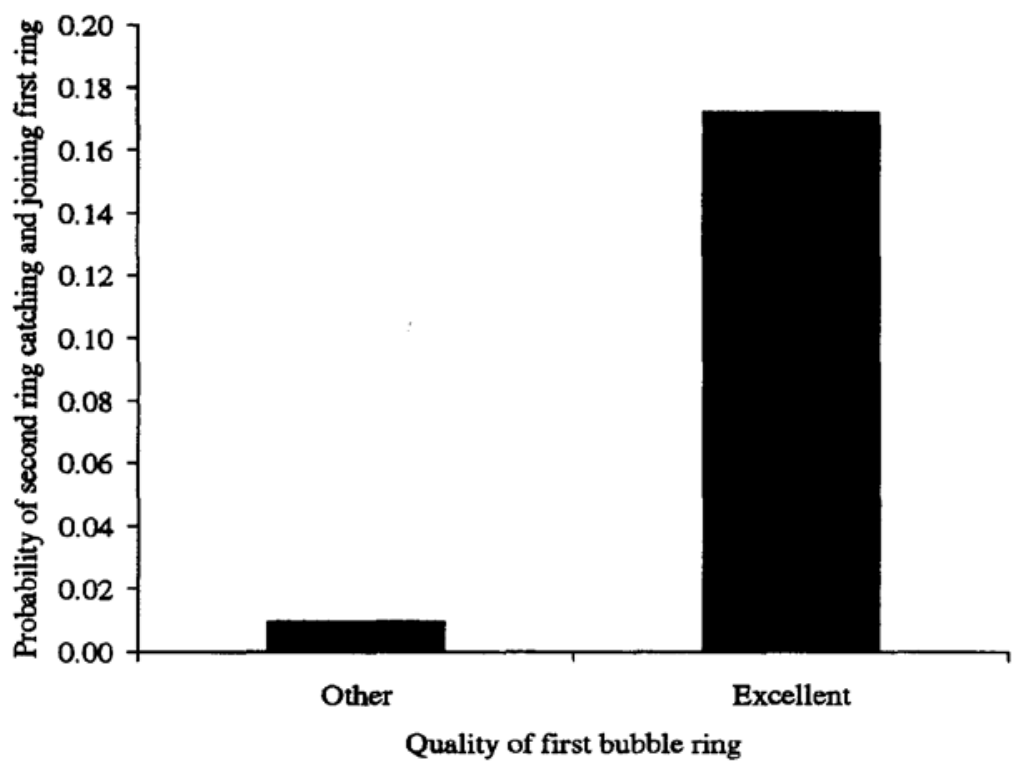

B

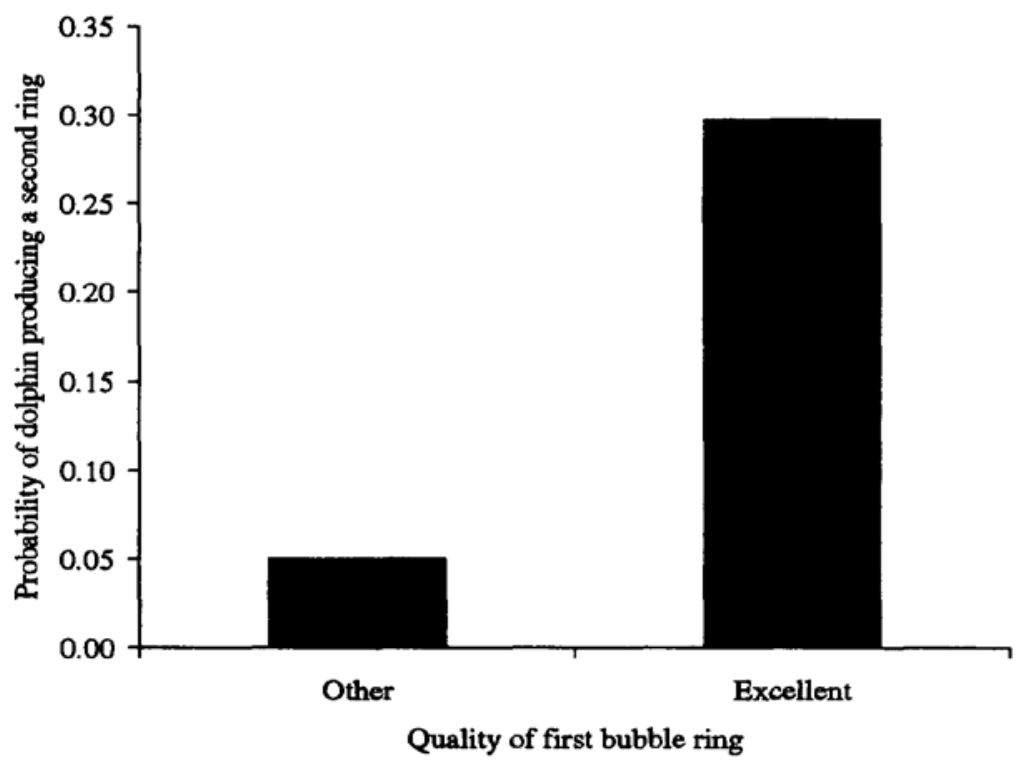


Figure 4. Logistic regression model for the association between bubble ring production by the dolphins and their location in the water column.

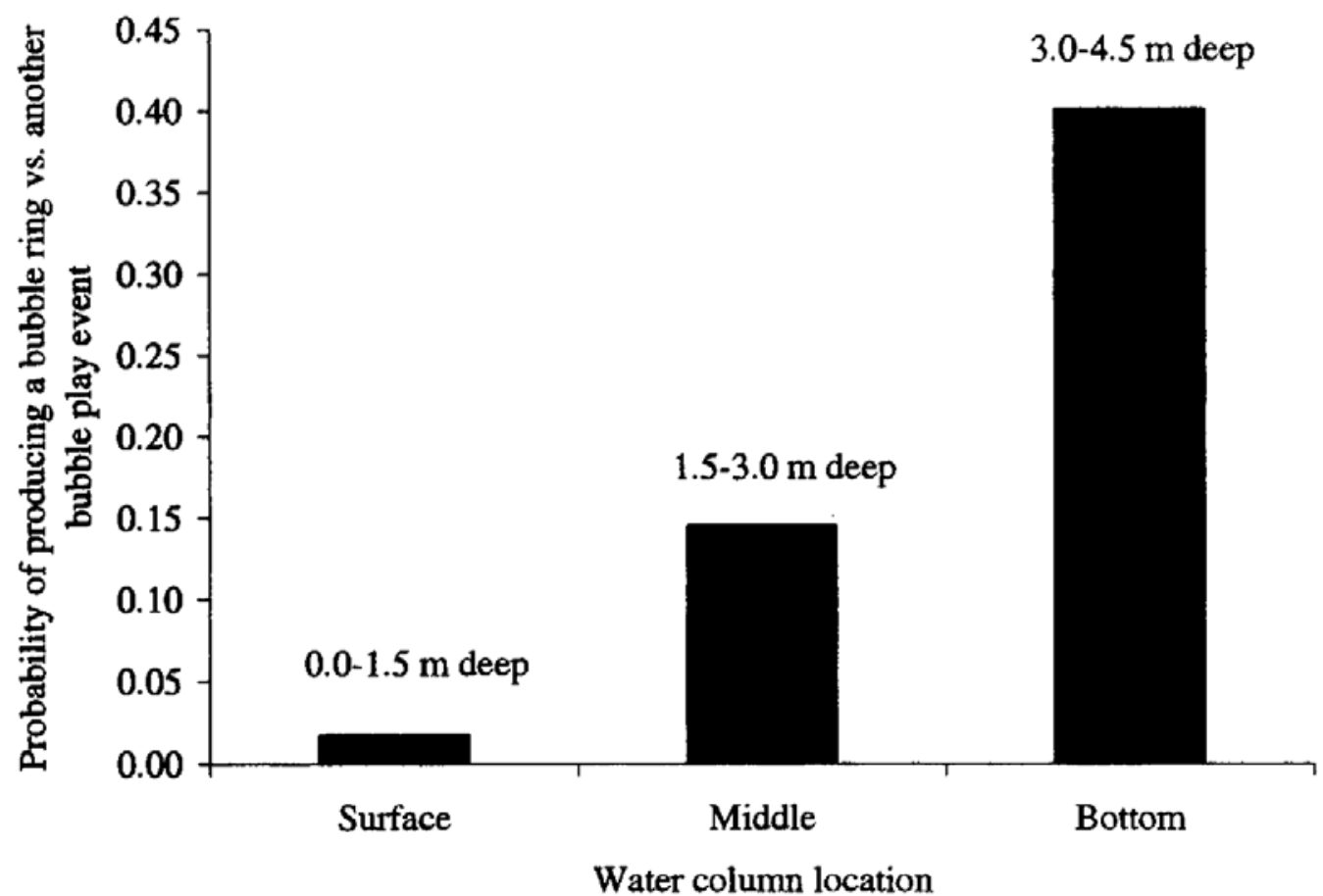

\section{Discussion}

The present results are consistent with the hypothesis that dolphins monitor the quality of their bubble rings and engage in low-level planning prior to actual bubble ring production. The qualitative observations demonstrated that there is flexibility in single and double bubble ring behavior, particularly with regard to the manipulations of double bubble rings after the two have joined.

Although the cognitive abilities of bottlenose dolphins have not been exhaustively explored, the existing literature suggests that bottlenose dolphins are capable of a number of possibly related cognitive capacities, such as self-monitoring, that may be consistent with the present findings. Smith et al. (1995) reported that bottlenose dolphins were capable of monitoring their own level of uncertainty in a psychophysical experiment. There is also suggestive evidence that dolphins recognize themselves in mirrors, although more systematic examination of this possibility is necessary (Marino, Reiss, \& Gallup, 1994; Marten \& Psarakos, 1994). In addition, the ability to report on the presence or absence of objects, which has been demonstrated in bottlenose dolphins (Herman, Richards, \& Wolz, 1984), arguably requires more than a rudimentary capacity for mental representation. Evidence for synchronized novel behaviors between two bottlenose dolphins suggests the possibility of foreplanning (Braslau-Schneck, 1994). Finally, a recent report presented the first systematic observations of tool use in wild bottlenose dolphins (Smolker, Richards, Connor, Mann, \& Berggren, 1997).

Within a broader comparative context, the cognitive literature on nonhuman primates offers the most extensive empirical basis for comparison. Within nonhuman primates, the pongids (great apes) represent a reasonable comparison group for dolphins, particularly on the basis of encephalization level (Marino, 1998). Currently, results converge on evidence for all of the aforementioned capacities in great apes, for 
example, tool use of various levels of complexity (e.g., Matsuzawa \& Yamakoshi, 1996; McGrew, 1992; Parker \& Gibson, 1977, 1979; Sugiyama, 1997), self-recognition (see Parker, Mitchell, \& Boccia, 1994, for a review), planning of tool-use activity (e.g., Boesch-Achermann \& Boesch, 1994; Limongelli, Boysen, \& Visalberghi, 1995), and physical causal understanding (Limongelli et al., 1995; Visalberghi \& Tomasello, 1998).

At this point, the present findings cannot reveal whether the observed behaviors are based on associative learning or a deeper cognitive understanding of physical events. This issue has been elegantly laid out by Kummer (1995) as a continuum from weak to strong causal knowledge. Some evidence for learning in bubble ring production does exist. Anecdotal observations suggest that infant dolphins watch and learn to produce bubble rings from their mothers (B. McCowan, personal observation). During ring play, mothers frequently watch and echolocate on their infants' first attempts at bubble ring production and produce bubble rings in response to their infants' attempts, which infants in turn echolocate on and watch float to the surface. As such, both the quality and the complexity of ring production appear to increase during development, perhaps as a result of this practice as well as the input from mothers. Yet, mothers are not the only individuals that serve as examples of high-quality ring production. For example, an infant housed separately from the juvenile males in this study was frequently observed to be watching the juveniles engaged in bubble ring play and subsequently practicing his own ring production at the gate that separated them.

In conclusion, the present findings suggest that dolphins anticipate their actions and monitor the outcome of their behavior during bubble ring production. Future studies of bubble play behavior in dolphins should focus on the ontogenetic development of this behavior so as to more conclusively address questions about the underlying cognitive basis for this behavior. On a more general level, the relationship between bubble play and manipulation and related cognitive capacities should be further explored.

\section{References}

Agresti, A. (1990). Categorical data analysis. New York: Wiley.

Altmann, J. (1974). Observational study of behavior: Sampling methods. Behaviour, 49, 227-265.

Antinucci, E (Ed.). (1989). Cognitive structure and development in nonhuman primates. Hillsdale, NJ: Erlbaum.

Antinucci, E (1990). Cognitive ontogeny in four primate species. In S. T. Parker \& K. R. Gibson (Eds.), Language and intelligence in monkeys and apes: Comparative developmental perspectives ( $\mathrm{pp}$. 157-171). New York: Cambridge University Press.

Boesch-Achermann, H., \& Boesch, C. (1994). Hominization in the rainforest: The chimpanzee's piece of the puzzle. Evolutionary Anthropology, 3, 9-16.

Braslau-Schneck, S. (1994). Innovative behaviors and synchronization in bottle-nosed dolphins. Unpublished master's thesis, University of Hawaii, Honolulu.

EGRET reference manual (Revision 4). (1997). Cambridge, MA: Cytel Software Corporation.

Fagen, R. (1981). Animal play behavior. New York: Oxford University Press.

Hall, S. L. (1998). Object play by adult animals. In M. Bekoff \& J. Byers (Eds.), Animal play: Evolutionary, comparative, and ecological perspectives (pp. 45-60). New York: Cambridge University Press. 
Herman, L. M. (1986). Cognition and language competencies of bottle-nosed dolphins. In R. J. Schusterman, J. A. Thomas, \& E G. Wood (Eds.), Dolphin cognition and behavior: A comparative approach (pp. 221-252). I-lillsdale, NJ: Erlbaum.

Herman, L. M., Richards, D. G., \& Wolz, J. P. (1984). Comprehension of sentences by bottlenosed dolphins. Cognition, 16, 129-219.

Kummer, H. (1995). Causal knowledge in animals. In D. Sperber, D. Premack, \& A. J. Premack (Eds.), Causal cognition: A multidisciplinary debate (pp. 26-39). Oxford, England: Clarendon Press.

Limongelli, L., Boysen, S. T., \& Visalberghi, E. (1995). Comprehension of cause-effect relations in a toolusing task by chimpanzees (Pan troglodytes). Journal of Comparative Psychology, 109, 18-26.

Lundgren, T. S., \& Mansour, N. N. (1991). Vortex ring bubbles. Journal of Fluid Mechanics, 225, 177-196.

Marino, L. (1998). A comparison of encephalization between odontocete cetaceans and anthropoid primates. Brain, Behavior and Evolution, 51,230-238.

Marino, L., Reiss, D., \& Gallup, G. G., Jr. (1994). Mirror self-recognition in bottlenose dolphins: Implications for comparative investigations of highly dissimilar species. In S. T. Parker, R. W. Mitchell, \& M. L. Boccia (Eds.), Self-awareness in animals and humans: Developmental perspectives (pp. 380- 391). New York: Cambridge University Press.

Marten, K., \& Psarakos, S. (1994). Evidence of self-awareness in the bottlenose dolphin (Tursiops truncatus). In S. T. Parker, R. W. Mitchell, \& M. L. Boccia (Eds.), Self-awareness in animals and humans: Developmental perspectives (pp. 361-379). New York: Cambridge University Press.

Marten, K., Shariff, K., Psarakos, S., \& White, D. J. (1996, August). Ring bubbles of dolphins. Scientific American, 275, 83-87.

Matsuzawa, T., \& Yamakoshi, G. (1996). Comparison of chimpanzee material culture between Boussou and Nimba, West Africa. In A. E. Russon, K. A. Bard, \& S. T. Parker (Eds.), Reaching into thought: The minds of the great apes (pp. 211-232). New York: Cambridge University Press.

McGrew, W. C. (1992). Chimpanzee material culture: Implications for human evolution. Cambridge, England: Cambridge University Press.

Parker, S. T., \& Gibson, K. R. (1977). Object manipulation, tool use, and sensorimotor intelligence as feeding adaptation in cebus monkeys and great apes. Journal of Human Evolution, 6, 623--641.

Parker, S. T., \& Gibson, K. R. (1979). A developmental model for the evolution of language and intelligence in early hominids. Behavioral and Brain Sciences, 2, 367-408.

Parker, S. T., Mitchell, R. W., \& Boccia, M. L. (Eds.). (1994). Self-awareness in animals and humans: Developmental perspectives. New York: Cambridge University Press.

Reiss, D. (1988). Can we communicate with other species on this planet? In G. Marx (Ed.), Bioastronomy--The next steps (pp. 253-264). Norwell, MA: Kluwer Academic.

Reiss, D. (1998). Cognition and communication in dolphins: A question of consciousness. In S. R. Hameroff, A. W. Kaszniak, \& A. C. Scott (Eds.), Toward a science of consciousness II: The second Tucson discussions and debates (pp. 551-560). Cambridge, MA: MIT Press. 
Reiss, D., McCowan, B., \& Marino, L. (1997). Communicative and other cognitive characteristics of bottlenose dolphins. Trends in Cognitive Sciences, 1, 140-145.

Ridgway, S. H. (1972). Homeostasis in the aquatic environment. In S. H. Ridgway (Ed.), Mammals of the sea: Biology and medicine (pp. 590--747). Springfield, IL: Charles C Thomas.

Rnsson, A. E., Bard, K. A., \& Parker, S. T. (Eds.). (1996). Reaching into thought: The minds of the great apes. New York: Cambridge University Press.

Searle, S. R., Casella, G., \& McCulloch, C. E. (1992). Variance components. New York: Wiley.

Smith, J. D., Schull, J., Strote, J., McGee, K., Egnor, R., \& Erb, L. (1995). The uncertain response in the bottlenosed dolphin (Tursiops truncatus). Journal of Experimental Psychology: General, 124, 391408.

Smolker, R., Richards, A., Connor, R., Mann, J., \& Berggren, P. (1997). Sponge carrying by dolphins (Delphinidae, Tursiops sp)---A foraging specialization involving tool use. Ethology, 103, $45 \mathrm{~A}$. A.55.

Sugiyama, Y. (1997). Social tradition and the use of tool composites by wild chimpanzees. Evolutionary Anthropology, 6, 23-27.

Tayler, C. K., \& Saayman, G. (1973). Imitative behavior by Indian Ocean bottlenose dolphins (Tursiops aduncus) in captivity. Behaviour, 44, 286-298.

Tomasello, M., \& Call, J. (1997). Primate cognition. New York: Oxford University Press.

Visalberghi, E., \& Tomasello, M. (1998). Primate causal understanding in the physical and psychological domains. Behavioural Processes, 42, 189-203. 